\title{
SELECTION OF FOREST SPECIES FOR USE IN URBAN ENVIRONMENT IN RELATION TO THEIR POTENTIAL CAPTURE TO HEAVY METALS
}

\author{
SAMARA T. ${ }^{1}$ \\ TSITSONI T., ${ }^{2}$
}

\author{
${ }^{1}$ Forest Research Institute of Thessaloniki \\ NAGREF, 57006 Vassilika, Thessaloniki \\ ${ }^{2}$ Laboratory of Silviculture, Faculty of Forestry and Natural Environment \\ Aristotle University of Thessaloniki Thessaloniki, Greece
}

Received: 01/10/2012

Accepted: 01/10/2014

*to whom all correspondence should be addressed:

Available online: 01/10/2014 e-mail: tsitsoni@for.auth.gr

\section{ABSTRACT}

The aim of this research is to study the behavior of different forest species in accordance with their ability to retain heavy metals on their leaves in order to select the most suitable species for urban and peri-urban use, which will contribute to the reduction of the continuously growing atmospheric pollution in the cities. Five species were studied: Cupressus arizonica, Albizia julibrissin, Platanus orientalis, Celtis australis and Ligustrum japonicum. 360 leaf samples were collected and two treatments (non-washed and washed sheets) were applied on them. The determinative estimation of the concentration of metals in the clear filtrate was carried out with the use of ICP-OES inductively coupled plasma optical emission spectrometry. In order to correlate the concentration of heavy metals in leaves with the silvicultural characteristics of species, the following characteristics were measured in 20 individuals per species: diameter at breast height, total height of tree, crown beginning height and crown's diameters. Statistically significant differences between the studied species were found for all metals. In addition, not a single species was found to retain the highest concentration of all. Metal concentration on leaves' surface in declining order was: $(\mathrm{Mn})>(\mathrm{Cu})>(\mathrm{Zn})>(\mathrm{Pb})>(\mathrm{Cr})>(\mathrm{Ni})>(\mathrm{Cd})$. The factor of height is significant both in the upper and lower layer of the crown. Broadleaves' species as Albizia julibrissin with compound leaves capture significant heavy metals as conifer species.

Keywords: urban green, silvicultural characteristics, air pollution, leaf morphology, crown surface.

\section{Introduction}

Quality of the environment is a matter of serious concern; especially today as the consequences of human intervention have already been evident. Although the environment is extremely valuable for every living organism, it is continuously destroyed by human activities (Davis et al., 2006). Roadsides in urban areas are usually polluted with heavy metals mostly derived from traffic: motor vehicle emissions, abrasion of tyres, brake linings as well as road surface, turbulence of dust due to vehicular movement, dispersion of construction material, etc. (Petrovsky and Ellwood, 1999; Gautam et al., 2004, Ovadnevaite et al., 2006).

Plants not only have an ornamental function in urban areas, but they also may improve the quality of urban life (Akbari, 2002; Brack, 2002). Moreover, plants can absorb and accumulate pollutants through their roots and leaves (Sawidis et al., 1995). Heavy metals can be dry deposited on plant surfaces and accumulated through sedimentation under the influence of gravity (Nowak, 2004). They can also be accumulated internal and/or be retention on leaves's surface (Gratani et al., 2000). 
Nowadays heavy metals are of high environmental concern. They are harmful to humans and animals and tend to bio-accumulate in the food chain (Yoon et al., 2006). The majority of plants can absorb metals and reach higher accumulation levels than those found in the air (Onder and Dursun, 2006). Urban vegetation can improve air quality in several ways. Trees can intercept atmospheric particles and absorb various gaseous pollutants. Various tree characteristics can alter wind profile or create local inversions in order to trap pollutants. As a consequence pollutant's removal is enhanced in local scale (Khan and Abbasi, 2001). During hot periods, trees can reduce the use of energy in buildings by shading them and altering air flows and thereby indirectly reduce pollutants emissions from power plants (Nowak, 1994).

In urban areas woody species are mostly suitable for monitoring metal pollution since lichens and mosses are often missing (Al-Alawi and Mandiwana, 2007).

The aim of this research is to study the behavior of different street trees and shrubs in accordance with their ability to capture heavy metals on their leaves. Selecting the most suitable species for urban and peri-urban use will contribute to the reduction of the continuously increasing urban atmospheric pollution. Four tree and one shrub species were studied: Cupressus arizonica, Albizia julibrissin, Celtis australis, Platanus orientalis and Ligustrum japonicum.

In particular, which factors affect the capture of heavy metals:

1. Is the species of trees or shrub?

2. Are the morphological characteristics of leaves (surface, compound or not)?

3. Which is the effect of crown height -from which leaves samples were collected?

4. Are the silvicultural characteristics of trees (crown length, crown surface area)?

\section{Materials and methods}

\subsection{Study site}

The research was carried out in Thessaloniki during August-September 2006. The city of Thessaloniki, is located in Northern Greece, is the second biggest city in Greece. It is a rapidly growing city and its present population is estimated above 1.000 .000 citizens. The city has Mediterranean climate with dry hot summers and mild winters. The average annual air temperature is $15.8^{\circ} \mathrm{C}$ with minimum average monthly temperature $5.9{ }^{\circ} \mathrm{C}$ (January) and maximum $25.9{ }^{\circ} \mathrm{C}$ (July). The average annual precipitation is $449.3 \mathrm{~mm}$ and relative humidity is 66.7\% (Sawidis et al., 1995; Batala and Tsitsoni, 2007; 2009).

The three sites which were chosen for this research are K. Karamanlis Avenue, Egnatia Street and M. Alexandrou Avenue. The sites were chosen because they are three major, heavy traffic roads of Thessaloniki according to data by Prefecture of Central Macedonia. Sawidis et al., (1995) reported that the main sources of heavy metal contamination in Thessaloniki are central heating, traffic load and road junctions. Important factor is the direction of the local winds (Vardaris) is from northwest to southwest; hence a constant increased contamination from the city industrial area which is sited at the west of the city.

\subsection{Sample collection and preparation}

Five species of trees and shrubs were selected to investigate the accumulation of metal in their leaves. The species that analyzed were Cupressus arizonica, Albizia julibrissin, Celtis australis, Platanus orientalis and Ligustrum japonicum. The aim of the collection was to cover a good range of species (broadleaves and coniferous, deciduous and evergreen) and it was based on different leaves' morphology (needlelamina, simple-compound) (Sawidis et al., 1995) and their different silvicultural treatment (Albizia julibrissin prunned). They also were chosen because of their presence in both urban and natural ecosystems; they have a widely geographical range and ecological distribution throughout the world; in addition their sampling, identification and cultivation is easy and inexpensive (Celik et al., 2005). 
Twenty trees from each species were selected in each of the considered sites (Taylor et al., 1990; Pourkhabbaz et al., 2010). From each tree two leaf samples were collected, one at the $1 / 3$ and the other at the $2 / 3$ of the tree crown height. The leaf samples where collected uniformly from around the tree and then were placed in paper bags. Leaves were mature without cuticle cracks, necrotic spots or lesions. The following silvicultural characteristics were also measured or calculated for each tree: diameter at breast height, total height, crown length, crown surface areas and crown diameters. The crown diameter measured from their project to the ground and through two vertical directions. Every length was measured with a hypsometer. Crown surface area ( $\mathrm{Ca}$ ) was calculated assuming the crown as a solid geometrical object. The regular geometrical objects were: conoid for Cupressus arizonica, hemisphere for Albizia jullibrissin and paraboloidal for Celtis australis and Platanus orientalis.

The leaf samples were divided into two sub-samples. The one was thoroughly washed with running distilled water to remove superficial leaf deposit, and the other remained untreated. Both washed and unwashed leaf samples were oven-dried at $80{ }^{\circ} \mathrm{C}$ for $24 \mathrm{~h}$, milled in a micro-hammer cutter and fed through a $0.2 \mathrm{~mm}$ sieve. Contamination from the micro-hammer cutter was negligible, since it was washed with distilled water after each use.

\subsection{Chemical analysis}

About $0.2 \mathrm{gr}$ of dried and milled plant material was ashed in furnace at $600^{\circ} \mathrm{C}$ for 5 hours. The capsule was removed from the furnace and was released reintroducing the sample to environmental temperature. Ten milliliters of concentrated $\mathrm{HNO}_{3}(2 \mathrm{~N})$ were added and the sample was heated at $80{ }^{\circ} \mathrm{C}$. The solution was cooled and was filtered through Whatman No. 42 diameter $125 \mathrm{~mm}$. The filtrate was diluted to $50 \mathrm{ml}$ of distilled water. Each final solution was analyzed for copper ( $\mathrm{Cu}$ ), lead $(\mathrm{Pb})$, chromium $(\mathrm{Cr})$, nickel ( $\mathrm{Ni})$, cadmium (Cd), manganese ( $\mathrm{Mn}$ ) and zinc ( $\mathrm{Zn})$.

In order to ascertain the accuracy of the method employed and calibrate for any slight contamination, three reference materials were used with every batch (Culture Labatory Proficiency-ALP program operated by Collaborative Testing Services Inc.): corn stalk from Connecticut, potato leaves from California and citrus leaves from California. Heavy metals concentrations were measured on inductively coupled plasma optical emission spectrometry ICP-OES (PS-1000 AT-Seqential Axial Transmittion Model with Autosampler of Leeman Labs).

\subsection{Statistical analysis}

The values were statistically evaluated with three-way analyses of variance (ANOVA), in the methodological frame of General Linear Models (GLM) (Zar, 1996; Rencher, 2000). Specifically, the data were assessed using linear model that included a factor between the experimental units (Factor "Species" with 5levels: Cupressus arizonica, Albizia julibrissin, Platanus orientalis, Celtis australis and Ligustrum japonicum and two factors inside the experimental units (Factor "Height with 2 levels: upper and lower, Factor "Treatment" with 2 levels: unwashed and washed). The experimental plan was considered as completely randomized factorial.

The total number of measurements of heavy metals concentrations for each species was 80 . The comparisons of means were realized by Bonferroni's multiple range test, for a $p=0.05$ confidence level. The Bonferroni's multiple range test was preferred in order to limit Type I Fault (Toothaker, 1993). The statistical analysis was conducted with the statistical software package of SPSS $\vee 15.0$ (SPSS Inc., Chicago: IL). The confidence level was predetermined in $p=0.05$.

\section{Results}

\subsection{Silvicultural characteristics}

The main silvicultural characteristics of forest species Cupressus arizonica, Albizia julibrissin, Platanus orientalis and Celtis australis are represented at Table 1. 
Table 1. Means and s. deviations of silvicultural characteristics of studied tree species.

\begin{tabular}{ccccccc}
\hline Forest Species & $\begin{array}{c}\text { Tree } \\
\text { diameter } \\
(\mathrm{cm})\end{array}$ & $\begin{array}{c}\text { Tree } \\
\text { height }(\mathrm{m})\end{array}$ & $\begin{array}{c}\text { Crown } \\
\text { height }(\mathrm{m})\end{array}$ & $\begin{array}{c}\text { Crown } \\
\text { diameter }(\mathrm{m})\end{array}$ & $\begin{array}{c}\text { Crown length } \\
(\mathrm{m})\end{array}$ & $\begin{array}{c}\text { Crown } \\
\text { surface }\left(\mathrm{m}^{2}\right)\end{array}$ \\
\hline $\begin{array}{c}\text { Cupressus arizonica } \\
\text { (conifer) }\end{array}$ & $24.03 \pm 4.06$ & $12.35 \pm 2.23$ & $9.83 \pm 2.00$ & $9.73 \pm 2.06$ & $4.59 \pm 1.27$ & $105.79 \pm 33.25$ \\
\hline $\begin{array}{c}\text { Albizia julibrissin } \\
\text { (broadleaf) }\end{array}$ & $16.73 \pm 5.46$ & $5.98 \pm 1.20$ & $3.90 \pm 0.94$ & $3.95 \pm 1.02$ & $6.5 \pm 1.86$ & $26.08 \pm 13.35$ \\
\hline $\begin{array}{c}\text { Celtis australis } \\
\text { (broadleaf) }\end{array}$ & $17.00 \pm 4.87$ & $6.75 \pm 1.52$ & $7.38 \pm 1.39$ & $4.38 \pm 1.39$ & $4.30 \pm 0.90$ & $31.83 \pm 10.61$ \\
\hline $\begin{array}{c}\text { Platanus orientalis } \\
\text { (broadleaf) }\end{array}$ & $59.92 \pm 20.32$ & $17.56 \pm 5.50$ & $14.50 \pm 5.20$ & $13.59 \pm 3.47$ & $13.53 \pm 2.91$ & $365.65 \pm 275.36$ \\
\hline
\end{tabular}

Albizia julibrissin is the only of the studied species that is systemically pruning every year.

\subsection{Species and heavy metals concentration}

The mean concentrations of manganese, zinc, lead, chromium, copper, cadmium and nickel of the tree leaves are given in figures 1a,1b,1c. For Ligustrum japonicum, the concentrations were determined only for the leaves from the lower part because it is a shrub.

The concentrations of the heavy metals were significantly related on the species and the height that leaves were collected. Only in cases of copper, cadmium and nickel the concentration of the heavy metal was dependent on the species, the height that the leaves were collected and the treatment that was used (washed-unwashed leaves).

Lead, chromium, copper, cadmium and nickel concentrations were greater in Cupressus arizonica, while zinc and lead concentrations were greater in Albizia julibrissin.

For all species the height (upper and lower part of the crown) that the leaves were collected is significantly different (ANOVA, $\mathrm{p}<0.001$ and the Bonferroni Test of multiple comparisons). For all studied species, except Albizia julibrissin, metal concentration was higher in the leaves that were collected from the upper crown. Higher concentrations were measured at Cupressus arizonica. Specifically, copper (Cu) $47.810 \mathrm{ppm}$ (for the leaves that there were not washed), lead (Pb) $27.470 \mathrm{ppm}$, cadmium (Cd) 1.237 ppm (for the leaves that there were washed), chromium ( $\mathrm{Cr}$ ) $7.958 \mathrm{ppm}$ and nickel (Ni) $3.296 \mathrm{ppm}$ (washed leaves).

\section{Discussion and conclusions}

In this research, metals mean concentration in leaves in declining order was: manganese $(\mathrm{Mn})>$ copper $(\mathrm{Cu})>$ zinc $(\mathrm{Zn})>$ lead $(\mathrm{Pb})>$ chromium $(\mathrm{Cr})>$ nickel $(\mathrm{Ni})>$ cadmium $(\mathrm{Cd})$. Respectively, Sawidis et al. (1995) for the city of Thessaloniki found the following declining order of metals mean concentration manganese $(\mathrm{Mn})>$ zinc $(\mathrm{Zn})>$ copper $(\mathrm{Cu})>$ cadmium $(\mathrm{Cd})$ for the eight plant species that they have studied. Pyatt (1999) studied the heavy metals concentration in Pinus nigra needles in Cyprus. Metals mean concentration in leaves in declining order was: iron $(\mathrm{Fe})>$ manganese $(\mathrm{Mn})=$ zinc $(\mathrm{Zn})>$ copper (Cu). Also, Pyatt (2001) studied, in another research, the heavy metals in leaves of Acacia retinoides in Cyprus. The declining order of heavy metals in control area was iron $(\mathrm{Fe})>$ manganese $(\mathrm{Mn})>$ copper $(\mathrm{Cu})=$ lead $(\mathrm{Pb})$ while in the polluted area the order changed in iron $(\mathrm{Fe})>$ lead $(\mathrm{Pb})>$ manganese $(\mathrm{Mn})>$ copper (Cu). The above species were considered that notably retain heavy metals (Pyatt, 1999, 2001). In another research, that was carried out in Denizli (Turkey), metals mean concentration in Robinia pseudoacacia leaves in declining order was iron $(\mathrm{Fe})>$ manganese $(\mathrm{Mn})>$ zinc $(\mathrm{Zn})>$ lead $(\mathrm{Pb})>$ copper (Cu) > cadmium (Cd) (Celik et al., 2005). 

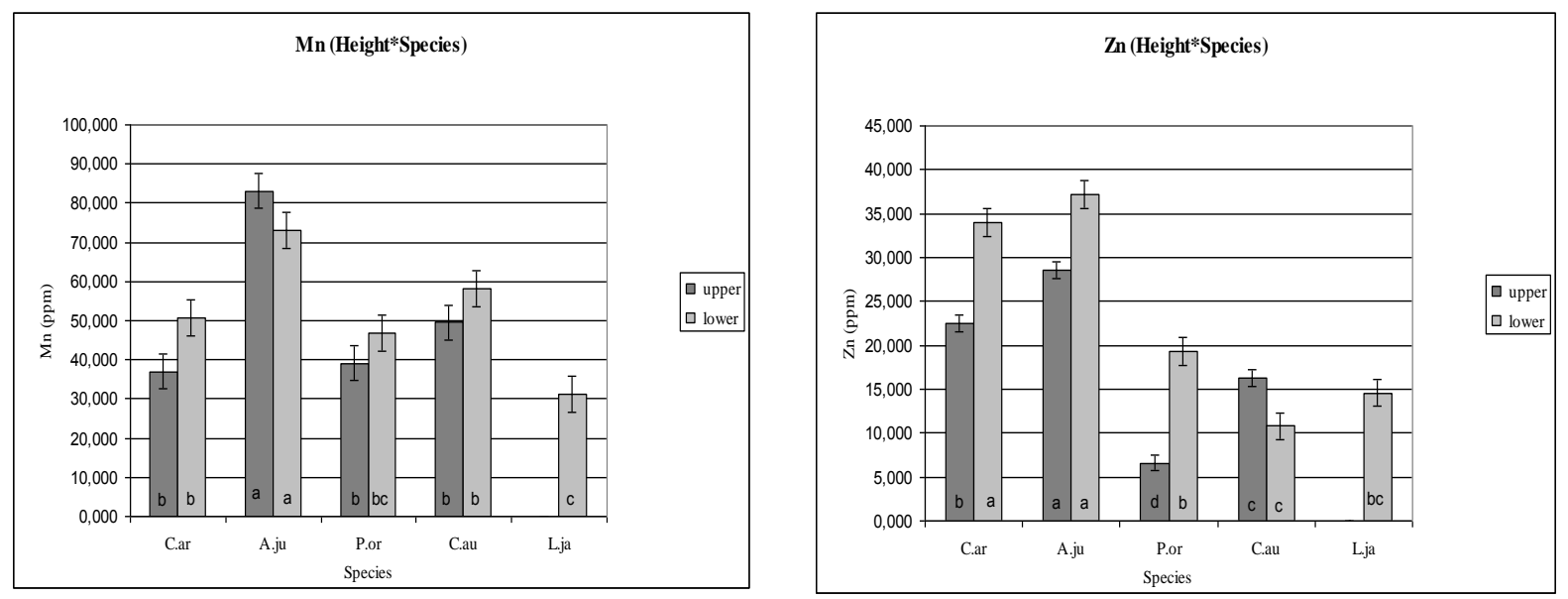

Figure 1a. Mean and s.e. of $\mathrm{Mn}$ and $\mathrm{Zn}$ concentrations of the five studied species. The differences in mean values of the metal concentration with different letters are significantly different (ANOVA, $p<0.001$ and the Bonferroni Test of multiple comparisons).
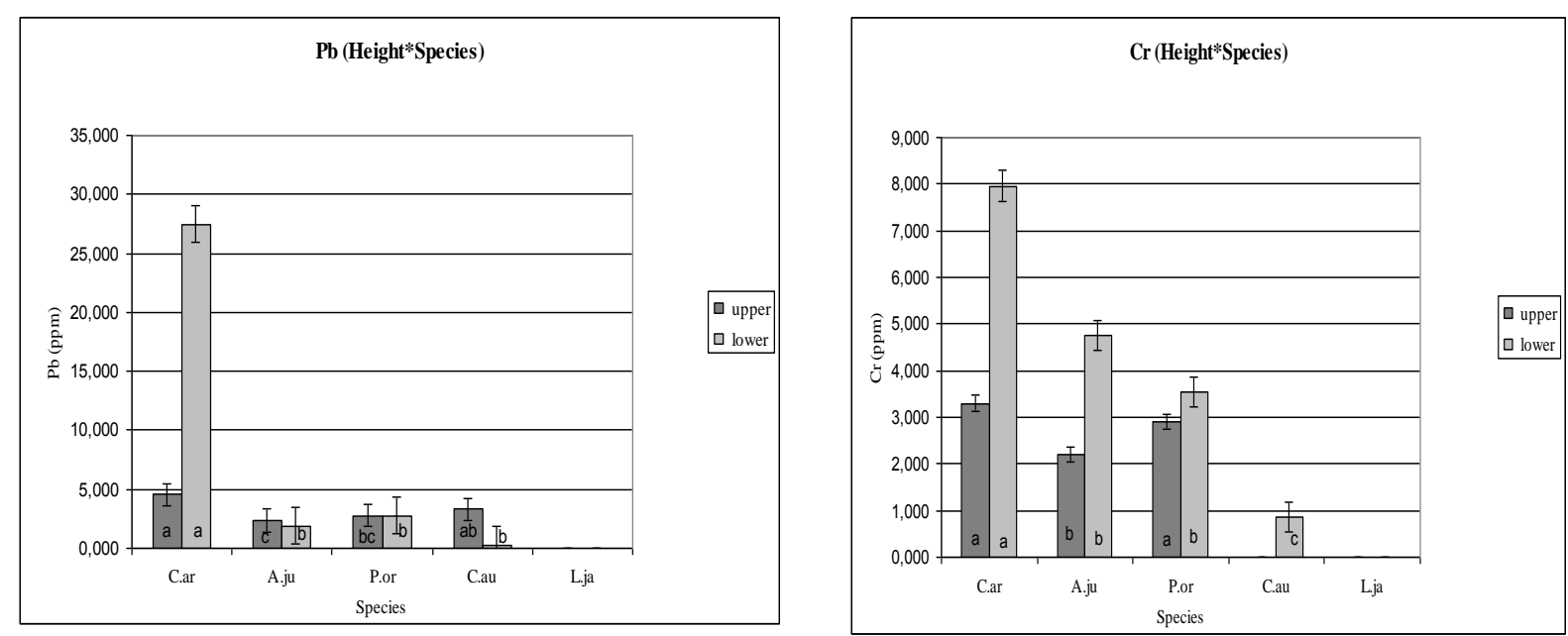

Figure 1b. Mean and s.e. of $\mathrm{Pd}$ and $\mathrm{Cr}$ concentrations of the five studied species. The differences in mean values of the metal concentration with different letters are significantly different (ANOVA, $p<0.001$ and the Bonferroni Test of multiple comparisons).

Sawidis et al., (1995) reported that copper (Cu) was presented with a small deviation among the studied species (Ligustrum japonicum, Nerium oleader, Olea europea, Pinus brutia, Platanus orientalis, Populus alba, Populus nigra and Robinia pseudoacacia) except from Neriun oleader and Platanus orientalis. In this research, copper $(\mathrm{Cu})$ presented high deviation between the species. Concretely, the higher mean concentration of copper $(\mathrm{Cu})$ was measured in Cupressus arizonica leaves and it was 36.150 ppm, while in Ligustrum japonicum was the smallest $1.095 \mathrm{ppm}$.

Hernandez et al. (1987) found that the lead (Pb) concentration in Nerium oleander leaves presented no difference between the samples that had been washed or not. The present research confirms the above conclusion since there wasn't found statistically significant difference for the lead $(\mathrm{Pb})$ between leaves that had not been washed and the ones that had, for all the studied species. For the other metals the factor 'treatment' (washed-unwashed) presented statistically significant differences.

As in most conifers, thus in Cupressus arizonica, the needles remain on tree from two to five years. These needles are exposed longer at polluted air than the leaves of broadleaves. Cupressus arizonica's needles are microscopic, abundant, blade shape, aquamarine, with obvious gland in ridge and with 
white resin (Athanasiadis, 1986). Sawidis et al. (2001) claims that the rough surface of needles and the presence of resin make surface adhesive contribute to the increase of heavy metals concentration.
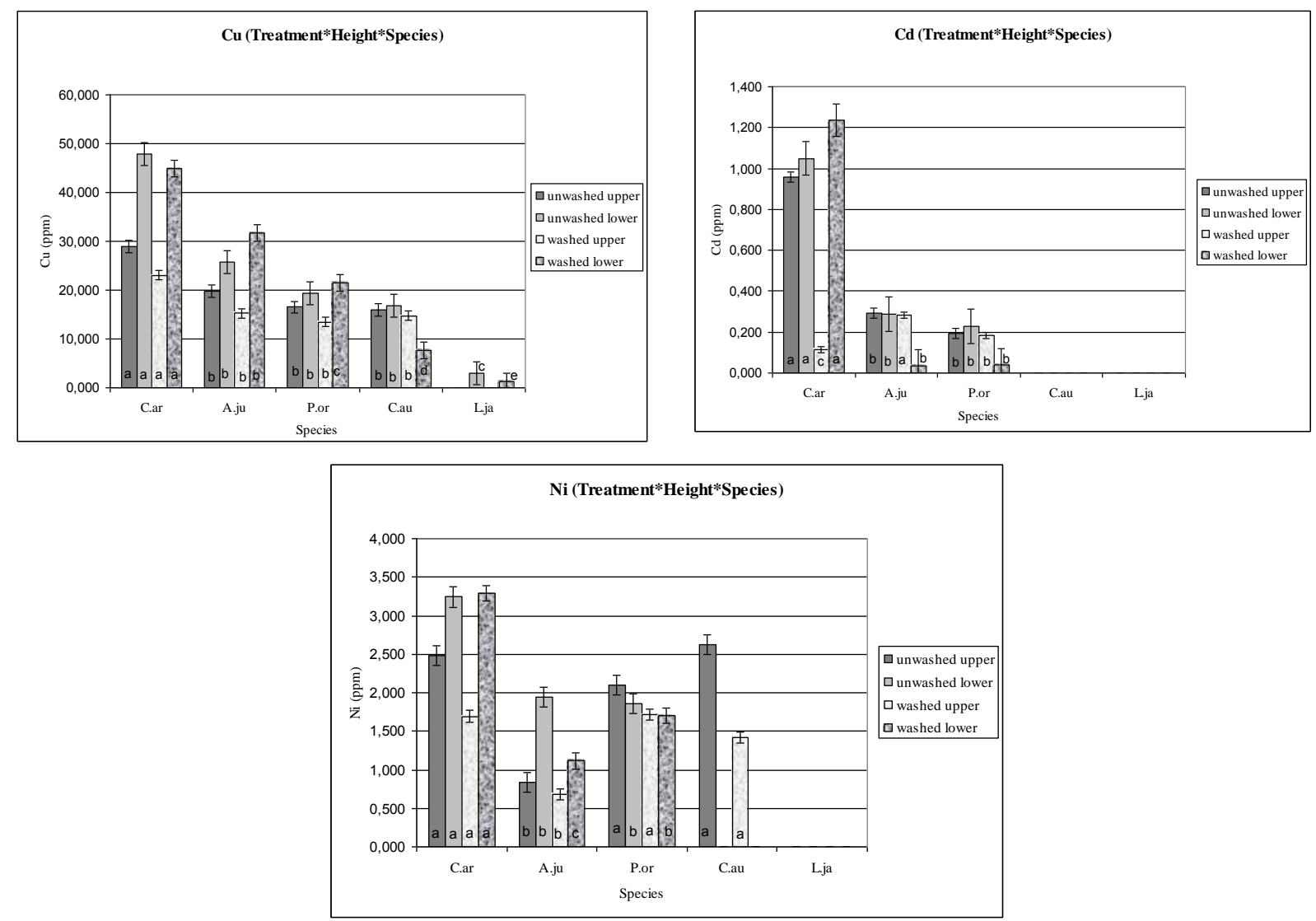

Figure 1c. Mean and s.e. of $\mathrm{Cu}, \mathrm{Cd}$ and $\mathrm{Ni}$ concentrations of the five studied species. The differences in mean values of the metal concentration with different letters are significantly different (ANOVA, $p<0.001$ and the Bonferroni Test of multiple comparisons).

The higher manganese $(\mathrm{Mn})$ and zinc $(\mathrm{Zn})$ mean concentrations were measured in Albizia julibrissin's leaves at the upper crown part. The higher manganese $(\mathrm{Mn})$ mean concentration 83,170 ppm had been measured in the leaves that had been collected in upper crown. Respectively, the higher zinc ( $\mathrm{Zn}$ ) mean concentration $28,627 \mathrm{ppm}$ had been measured in the leaves that had been collected from the upper crown for Albizia julibrissin. Albizia julibrissin is the only of the species that is systematically pruning. According to Martin and Coughtrey (1982) exterior crown leaves have increased ability to detention elements from atmosphere. Consequently, further research is required on how pruning influences the detention of heavy metals. Sawidis et al., (2001), found for Robinia pseudoacacia also for Albizia julibrissin that the present of aphids make leaves surface more adhesive having as result the easier detention of heavy metals.

Platanus orientalis with its big crown can participate considerably in the improvement of air pollution (Pourkhabbaz et al., 2010). According to Nowak (1994) a big tree with breast diameter $76 \mathrm{~cm}$ can remove 70 times more air pollutants from air in Chicago (USA) than a tree with breast diameter $8 \mathrm{~cm}$. Also Yang and Mc Bride (2003) reported that intense pruning decreases the ability of big trees to detention air pollutants. Sawidis et al. (1995) and Beckett et al. (2000 a,b,c) found that the more powerful accumulation of metals presented in species that had rough leaves' surface. In Platanus orientalis the dense pilled leaves and the prominent reticulate form of veins trap and retain air pollutants effectively (Dickinson et al., 1991; Pourkhabbaz et al., 2010). In the present research Platanus orientalis detention the second higher concentration of nickel $(\mathrm{Ni})(1,847 \mathrm{ppm})$ among the five studied species. 
Celtis australis has particularly rough leaves. It withheld the higher manganese $(\mathrm{Mn})$ concentration (31,319 ppm in the leaves that were collected at lower crown), higher even from the conifer that was studied (Cupressus arizonica). Kovács (1992 a,b) proposes tree species for their detergent role into urban environment, among them is Celtis sp.

The waxy cuticle of Ligustrum japonicum which forms a smooth sheet over the epidermal cells enables the fast removal of the particles by the rain (Sawidis et al., 1995). This species should be used in places like road axes where the concentrations of heavy metals are higher consequently. According to Sawidis et al., (1995) the most important factor for the pollution in local scale from vehicles exhausts, are the places near traffic lights where exists permanent vehicles halt of despite the total circulatory pressure of particular road artery. In fact in the present research higher heavy metal concentration was measured in trees and bushes of studied species that were found near traffic lights. Also, Ligustrum japonicum is suitable for such places for an additional reason: it can be pruned in any form so it does not create problems to the optical contact of drivers at traffic lights.

The species Cupressus arizonica withhold the largest concentrations of the metals copper $(\mathrm{Cu})$, lead $(\mathrm{Pb})$, cadmium (Cd) chromium ( $\mathrm{Cr}$ ) and nickel (Ni) and the species Albizia jullibrissin the higher concentrations of manganese $(\mathrm{Mn})$ and zinc $(\mathrm{Zn})$.

This study gives useful information about how procedures in sample collection should be carried out in future researches. Additional research is required on the effect of trees pruning in metal retention by the leaves. According to Markert (1993) and Witting (1993), the basic criteria for the selection of a species as a biomonitor are: the large number of individuals all over the monitoring area, having a wide geographical range, being easy and inexpensive to sample and presenting no identification problems. The five species in our study satisfy all these criteria and our study fully supports the view that they can be used as biomonitors all around Greece, Europe, Asia, Africa and the U.S.A. Also the methodology is recommended for similar studies because of the significant information that concern the factor: crown height.

The tree or shrub species affect the capture of heavy metals. Not only evergreen species but and broadleaves' species as Albizia julibrissin capture significant heavy metals on their leaves.

Albizia jullibrissin with compound leaves capture the higher manganese $(\mathrm{Mn})$ and zinc $(\mathrm{Zn})$ mean concentrations at the upper crown part.

It is the first time, that the effect of crown height -from which leaves samples were collected- was studied. The maximum of heavy metals concentration were measured at the leaves that were collected at the upper part of the crown.

The morphological characteristics of leaves (simple or compound) and not the silvicultural characteristics of species (crown length and surface) are the factors that influence their ability to capture of heavy metals.

\section{References}

Akbari $\mathrm{H}$. (2002), Shade trees reduce building energy use and $\mathrm{CO}_{2}$ emissions from power plants, Environmental pollution, 116, 119-126.

Al-Alawi M. and Mandiwana K. (2007), The use of Alepo pine as a bio-monitor of heavy metals in atmosphere, Journal of Hazardous Materials, 148, 43-46.

Athanasiadis N. (1986), Forest Botanic. Part II. Eds. Giachoudis-Giapoulis, Thessaloniki.

Batala E. and Tsitsoni T. (2007), Research on urban greenery of representative types in the avenues of the municipality of Thessaloniki. Proceedings of 1st International Conference on Environmental Management, Engineering, Planning and Economics. Skiathos, June 24-28. pp. 2979-2984.

Batala E. and Tsitsoni T. (2009), Street tree health assessment system a tool for study of urban greenery, Int. J. Sus. Dev. Plann, 4(4), 1-12. 
Beckett K.P., Free-Smith P. and Taylor G. (2000a), Effective tree species for local air-quality management, Journal of Arboriculture, 26, 12-19.

Beckett K.P., Free-Smith P. and Taylor G. (2000b), The capture of particulate pollution by trees at five contrasting urban sites, Arboricultural Journal, 24, 209-230.

Beckett K.P., Free-Smith P. and Taylor G. (2000c), Particulate pollution capture by urban trees: effect of species and windspeed, Global Change Biology, 6, 995-1003.

Brack C.L. (2002), Pollution mitigation and carbon sequestration by an urban forest, Environmental pollution, 116, 195-200.

Celik A., Kartal A.A., Akdogan A. and Kaska Y. (2005), Determining the heavy metal pollution in Denizli (Turkey) by using Robinia pseudo-acacia L., Environment International, 31, 105-112.

Davis E.B. (2006), Trends in Environment Research, Davis E.B. (Ed.), Nova Science Publishers Inc., New York, USA.

Dickinson N.M., Turner A.P. and Lepp N.W. (1991), Survival of trees in a metal-contaminated environment. Part III, Water Air Soil Pollution, 57-58, 627-633.

Gautam P., Blaha U., Appel E. and Neupane G. (2004), Environmental magnetic approach towards the quantification of pollution in Kathmandu urban area, Nepal, Physics and Chemistry of the Earth, 29(13,14), 973-984.

Gratani L., Crescente M.F. and Petruzzi M. (2000), Relationship between leaf life - span and photosynthetic activity of Quercus ilex in polluted urban areas (Rome), Environmental pollution, 110, 19-28.

Hernandez L.M., Rico C., Gonzalez J. and Hernan A. (1987), Environmental contamination by lead and cadmium in plants from an urban area of Madrid, Spain, Bulletin of Environmental Contamination and Toxicology, 38, 203-208.

Khan F.I. and Abbasi S.A. (2001), Effective design of greenbelts using mathematical models, Journal of Hazardous Materials B., 81, 33-65.

Kovács M. (1992a), Biological indicators in environmental protection. Ellis Horwood, New York.

Kovács M. (1992b), Trees as biological indicators. Biological indicators in environmental protection. Kovács, M. (ed.), Ellis Horwood, New York.

Markert B. (1993), Plants as Biomonitors/Indicators for Heavy Metals in the Terrestrial Environment. VCH Press, Weinheim.

Martin M.H., Coughtrey P.J. (1982) Biological monitoring of heavy metal pollution. Land and air. Applied Science Publishers, London, New York, p. 475.

Nowak D.J. (1994) Air pollution removal by Chicago's urban forest. McPherson, E.G., Nowak, D.J., Rowntree, R.A., (Eds.), Chicago's Urban Forest Ecosystem: Results of the Chicago's Urban Forest Climate Project. General Technical Report NE-186. US Department of Agriculture, Radnor, Pennsylvania, pp.63-84.

Nowak D.J. (2004) Assessing environmental fuctions and values of veteran tree. Nicolotti G., Gonthier (eds.). Processing of the International Congress on the Protection and Expoitation of Veteran Trees. Region Piemonte and University of Torino, Torino, Italy, pp.45-49.

Onder S. and Dursun S. (2006), Airborne heavy metal pollution of Cendrus libani (A. Rich.) in the city centre of Konya (Turkey), Atmospheric Environment, 40, 1122-1133.

Ovadnevaite J., Kvietkus K. and Marsalka A. (2006), 2002 summer fires in Lithuanian: impact on the Vilnius city air quality and the inhabitant's health, Sci. Total Environ., 356, 11-21.

Petrovsky E. and Ellwood B.B. (1999) Magnetic monitoring of pollution of air, land and waters. Maher B.A. and Thompson R. (Eds.), Quaternary Climates, Environments and Magnetism. Cambridge University Press, Cambridge, pp. 279-322.

Pourkhabbaz A., Rastin N., Olbrich A., Langenfeld-Heyser R. and Polle A. (2010), Influence of environmental pollution on leaf properties of urban plane trees, Platanus orientalis L., Bull Environmental Comtam. Toxicology, 85(3), 251-255.

Pyatt F.B. (1999) Comparison of foliar and stem bioaccumulation of heavy metals by Corsican pines in the Mount Olympus Area of Cyprus, Ecotoxicology Environmental Safety, 42, 57-61. 
Pyatt F.B. (2001), Copper and lead bioaccumulation by Acacia retinoides and Eucalyptus torquatain sites contaminated as a consequence of extensive ancient mining activities in Cyprus, Ecotoxicology Environmental Safety, 50, 60-64.

Rencher A. (2000) Linear Models in Statistics. New York: John Willey \& Sons, Inc.

Sawidis T., Chettri M.K., Papaioannou A., Zachariadis G. and Stratis J. (2001), A study of metal distribution from lignite fuels using trees as biological monitors, Ecotoxicology and Environmental Safety, 48, 27-35.

Sawidis T., Marnasidis A., Zachariadis G. and Stratis J. (1995), A study of air-pollution with heavy-metals in Thessaloniki City (Greece) using trees as biological indicators, Archives of Environmental Contamination and Toxicology, 28, 118-124.

Taylor H.J., Ashmore M.R. and Bell J.N.B. (1990) Air pollution injury to vegetation. London: IEHO.

Toothaker L. (1993) Multiple Comparison Procedures. Newbury Park: Sage Publications, Inc.

Witting R. (1993) General aspects of biomonitors heavy metals by plants, Plants as Biomonitors/Indicators for Heavy Metals in the Terrestrial Environment. VCH Press, Weinheim, pp. 3-28.

Yang J. and McBride J. (2003), A unique technique for tree planting in Beijing, Arboriculture Journal, 27, 1-10.

Yoon J., Cao X., Zhou Q. and Ma L. (2006), Accumulation of Pb, Cu, and $\mathrm{Zn}$ in native plants growing on a contaminated Florida site, Science of the Total Environment, 368 (2-3), 456-464.

Zar J. (1996) Biostatistical Analysis. New Jersey: Prentice-Hall International, Inc. 